This paper is part of the Proceedings of the $3^{\text {rd }}$ International Conference on Design,

\title{
Development of innovative urban water efficiency systems and a four-legged education curriculum addressing water reduction, harvesting, reuse, and energy generation technologies
}

\author{
N. Chalfoun ${ }^{1} \&$ O. Youssef ${ }^{2}$ \\ ${ }^{I}$ College of Architecture, Planning, and Landscape Architecture, \\ University of Arizona, USA \\ ${ }^{2}$ Arid Lands Resource Sciences, University of Arizona, USA
}

\begin{abstract}
Urbanization is no longer a gradual population shift, the world is undergoing major development and is utilizing technology and energy to increase the rate of construction. With changes in today's society and culture, people are rapidly shifting from living in rural areas to urbanized environments. The world's demand for energy and water has increased. Energy and water are fundamental components of life, they can no longer be considered separated. The building sector is changing the future of energy, accounting for almost $40 \%$ of energy consumption in the World. In addition, access to sufficient quantities of acceptable water quality is a basic need for human beings and a pre-requisite to sustain development and welfare. Human activities and consumption are also major contributors to climate change. Scientists have predicted that these effects will cause a rise in sea levels, more frequent floods, and droughts, which in return affects our initial water sources. The loss of water support below ground due to urban growth is becoming a geologic hazard, which may lead to land subsidence and Earth fissures being steadily encroached upon. Hence, mitigation through governmental decisions and policies as well as new technology and education will have the greatest impact on the building sector. This paper describes the development of innovative urban water efficiency systems and a four-legged education curriculum addressing: (1) water reduction, (2) water harvesting, (3) water reuse, and (4) water energy generation technologies. Focusing on the effective use of water to practice a more
\end{abstract}


sustainable approach to new construction and urbanization, utilizing effective and efficient energy saving management in order to optimize building performance. The curriculum includes emphasis on environmental benefits that integrates water saving strategies to assessment of thermal conditions in and around spaces. Developed technologies and curricula materials include calculative methods, use of computer simulation, design monographs, and hands on inquiry based learning through laboratory sessions. Results and conclusion are included in the paper.

Keywords: urbanization, energy, water efficiency, water reduction, water harvesting, water reuse, water/energy generation, sustainable construction, building performance, curriculum, thermal comfort.

\section{Introduction}

The earth holds about 332.5 million cubic miles of water [1]. Although this statement implies availability of large quantities of water sources, many current desert communities are in jeopardy from lack or diminishing of water supplies for survivorship.

People believe that we are losing water, and that at some point we could completely run out of water. However, due to the Earth's natural water cycle; water isn't still and is constantly relocating from one place to another [2]. The misperception about losing water is false, but the true problem is not having good quality, drinkable, or freshwater. About eight million cubic miles the total water is freshwater, most of it is stored in underground reservoirs, permanent ice, snow covers, lakes, and rivers [1] (see Figure 1).

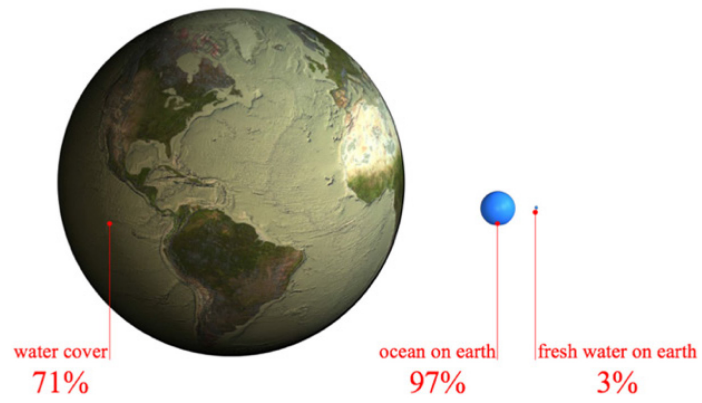

Figure 1: Water availability.

Water is not merely for human consumption, but is essential in the construction, and operation of the built environment [3]. The fact that producing energy consumes water, the pumping, treating and distributing of water in turn requires energy. In other words, water is an energy issue and energy is a water issue (see Table 1).

Throughout the 20th century, the connections between water and energy were largely ignored. Water supply and distribution systems were designed and constructed with the assumption that energy and water would be cheap and 
Table 1: Water energy nexus.

\begin{tabular}{|l|l|}
\hline Water use for energy & Energy use for water \\
\hline Thermoelectric Cooling & Pumping \\
Hydropower & Treatment \\
Extraction and Mining & Transport \\
Fuel Production & Wastewater collection \\
Emission Controls & Wastewater treatment \\
\hline
\end{tabular}

abundant. However, they are fundamental components of our 21 st century life, and can no longer be considered separated.

As we transform land from desert to urban we increase the urban heat island effect in retrospect of water allocation and future state developments (see Figure 2 ). Developers can no longer count on historic data to inform urban design decisions. Urban environmental water supply could be used to aid design officials on water risk management, there is a large percentage of water being consumed for urban areas, and therefore has a post occupancy effect on water cost [4].

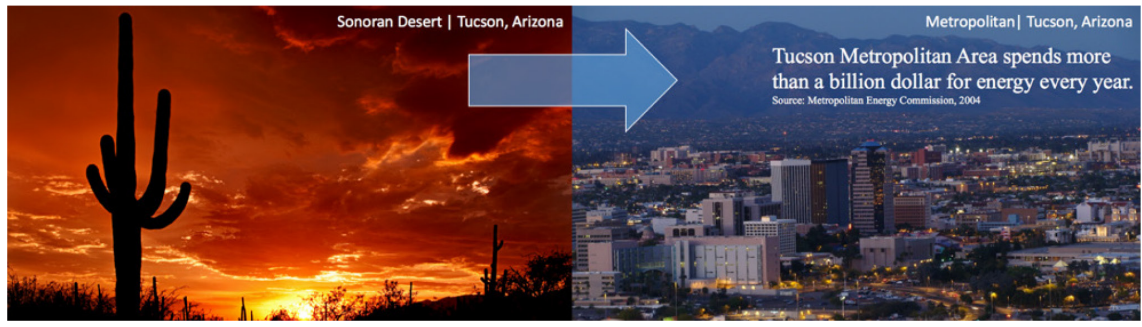

Figure 2: Desert to urban.

\section{Water curriculum and application}

Until today, in architecture education, "water efficiency" principles have not been effectively taught in tandem with "energy conservation" though they are strongly related. In response, the authors have developed an innovative architecture education curriculum [5] that focuses on efficient use of water in desert communities and its impact on energy consumption and building performance. This education curriculum addresses the issue of water/energy nexus through a proposed four-legged body of knowledge (see Figure 3) addressing (1) water reduction, (2) water harvesting, (3) water reuse, and (4) water energy generation technologies. Although water reduction and water harvesting have recently become more common in building design, water reuse and water energy generation are relatively newer technologies that demonstrates greater promise to contribute to the affordability of water and its use as an alternative energy source.

The curriculum also includes environmental benefits by integrating water saving strategies that modify thermal conditions inside spaces. These modified environments would otherwise use conventional HVAC, while the saved water 


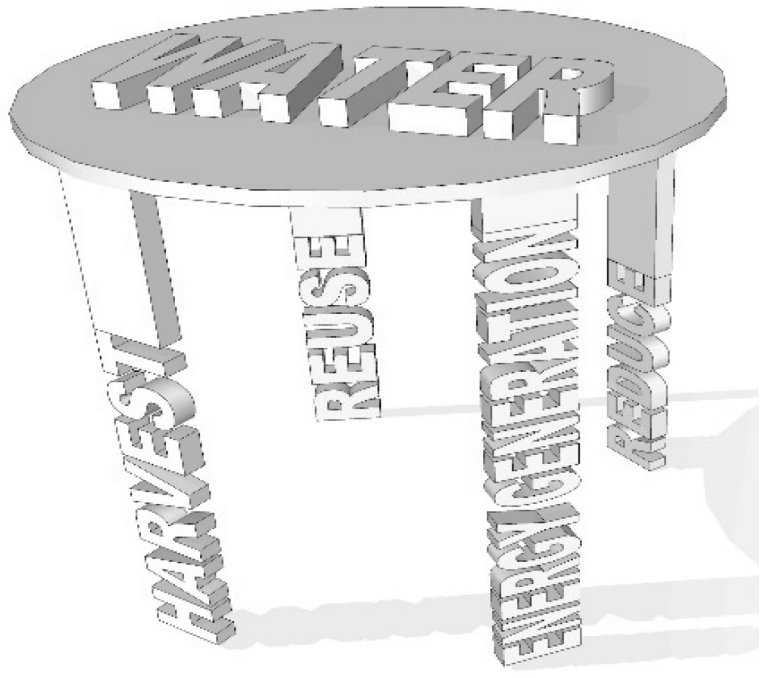

Figure 3: Four-legged curriculum.

will facilitate opportunities for exterior landscape development. All presented technologies are supported through calculative methods, use of computer simulation, design monographs, and hands on inquiry based learning through laboratory sessions.

As buildings are responsible for about half of all the energy consumption in the United States, the reduction of energy is crucial to our lifestyle [6]. The reduction of water consumption for construction and architectural development will have a great impact on water conservation efforts. The proposed four-legged body of knowledge addresses:

1) water reduction,

2) water harvesting,

3) water reuse, and

4) water energy generation.

The following sections demonstrate the four curriculum topics as well as sample skill development exercises that help course participants understand the content and build appropriate skills.

\subsection{Water reduction}

This is the most important phenomenon as it is based on the notion of conservation first. If we reduce our water consumption, we will mitigate the need of increasing our supply. There are two aspects to water conservation: (1) Human factor: how users can change their usual operation to reduce water consumption through conservation and management, and (2) Technology: for indoor and outdoor water use. The prime focus in water efficiency will be on potable water. 
Table 2: Water conservation curriculum topics.

\begin{tabular}{|l|l|}
\hline Human factor & Use of technology \\
\hline Time of use & Water saving heads \\
Frequency of use & Low-Flow Fixtures \\
Number of Laundry loads & Insulated Water pipes \\
Time of irrigation & Drought resistant plant \\
Pipe Leaks & Xeriscape \\
Water Metering & Advanced dripping systems \\
\hline
\end{tabular}

A combination of both factors would optimize water consumption in the built environment. For example, one week of five-minute showers in a 600 gallon shower stall using a regular showerhead would consume about 150 gallons of water, however using a low-flow showerhead water consumption could be reduced to 80 gallons.



Figure 4: Water reduction.

\subsection{Water harvesting}

The built environment has grown rapidly over the last 50 years, resulting in large areas of land being paved over with impermeable materials that causes less ground water recharge. Figure 5 demonstrates that water runoff can reach $100 \%$ in constructed land.

With climate change projected to lead to increasingly warmer and wetter weather conditions, rainfall is likely to continue to rise. As a result, many experts analyse that wide-scale flooding will become ever more frequent.

This proposed section will focus on two main topics on water harvesting, one from roof tops and the other from building's site.

\subsubsection{Roof top rainwater harvesting}

In rooftop harvesting, the roof becomes the catchment system, and the rainwater is collected from the roof of the house/building. It can either be stored in a tank or 


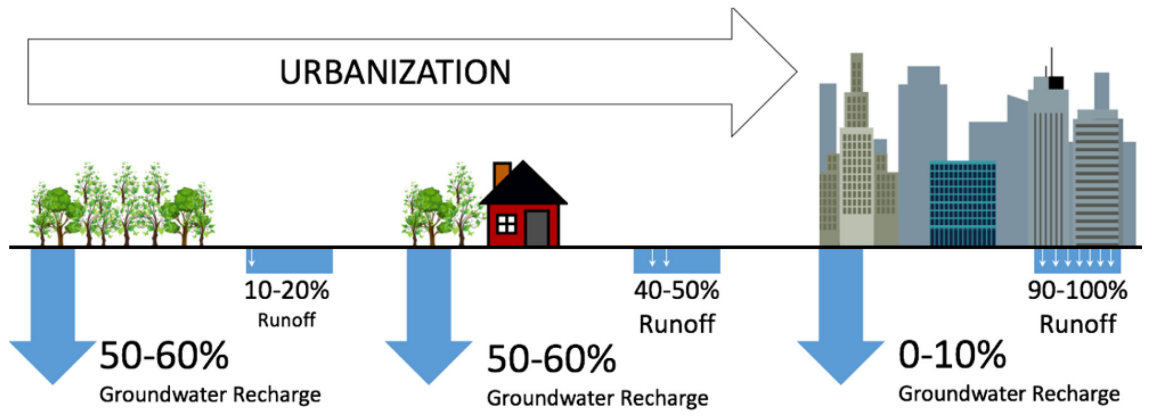

Figure 5: Storm water runoff.

diverted to an artificial recharge system. This method is less expensive and very effective, if implemented properly it helps in augmenting the ground water level of the area.

Table 3: Methods and components of rainwater harvesting.

\begin{tabular}{|l|l|}
\hline Methods & Components \\
\hline Storage of direct use & Catchment \\
Recharging ground water aquifers & Transportation \\
Recharging bore wells & First flush \\
Recharge pits & Filters \\
Soak way or recharge shafts & $\bullet \quad$ Sand gravel \\
Recharging of dug wells & $\bullet \quad$ Charcoal \\
Recharge trenches & $\bullet \quad$ PVC pipe filter \\
Percolation tank & $\bullet \quad$ Sponge filter \\
\hline
\end{tabular}

With ground space being covered up with the building footprint, and not as suitable for water collection, roofs can become the largest surfaces appropriate for rainwater collection. Depending on the region, the amount of cubic feet of water that could potentially be collected from the roof is the function of the frequency of rain in that region.

For example, in Tucson, Arizona with the total annual average rainfall is 11.5" per year. A $2000 \mathrm{ft}^{2}$ of clear residential roof area could be a roof-top rain-water collection system that collects an annual $23,000 \mathrm{ft}^{3}(=2000 \times 11.5)$ of rainwater $[7]$.

\subsubsection{Surface runoff harvesting}

Around buildings, especially in urban areas, rainwater flows as surface runoff and can be captured and used on site and/or to recharge aquifers by adopting appropriate methods. Capturing storm water runoff from impervious surfaces in urban and suburban areas when it rains - whether by directing the runoff to open spaces and allowing it to infiltrate into the ground to recharge groundwater supplies or by harvesting the runoff in cisterns for direct use in non-potable 


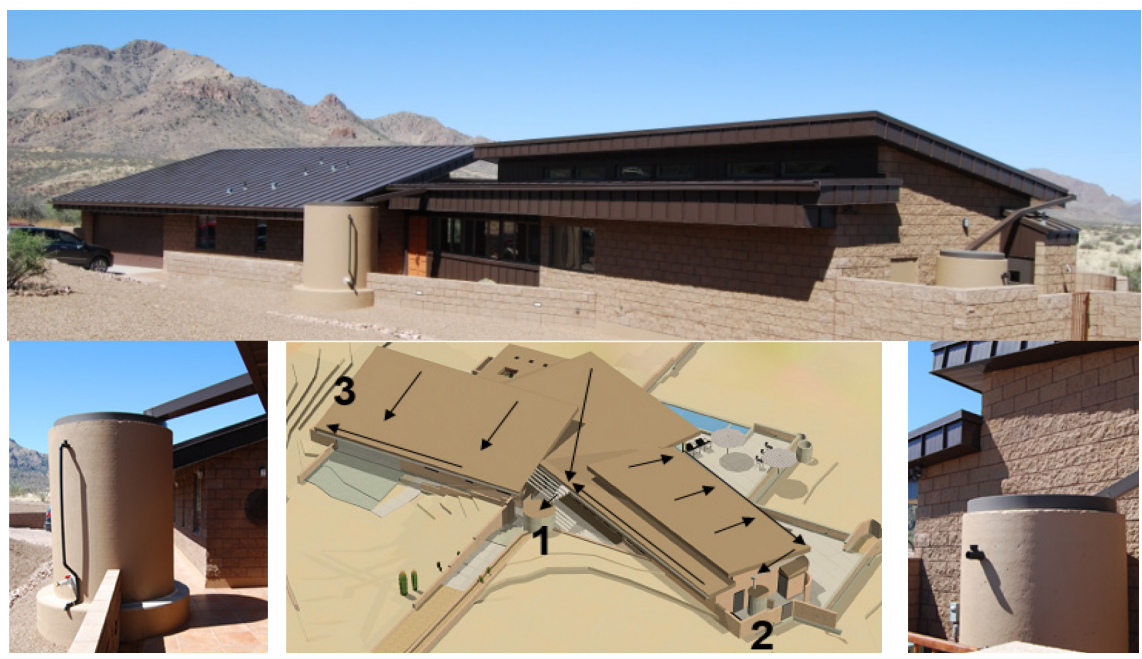

Figure 6: Rain water harvesting.

applications. This technology can be used to increase urban areas water supplies dramatically. For example, in southern California and the San Francisco Bay Area, capturing runoff using these approaches can increase water supplies by as much as 630,000 acre-feet each year. Capturing this volume, roughly equal to the amount of water used by the entire City of Los Angeles annually, would increase the sustainability of California's water supplies while at the same time reducing a leading cause of surface water pollution in the state.

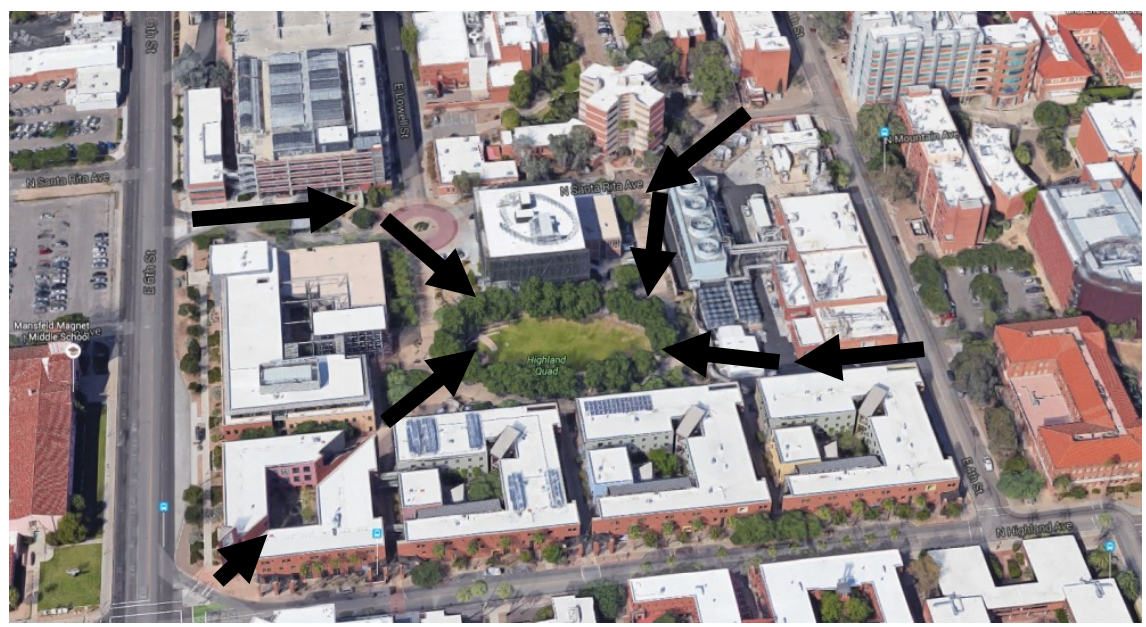

Figure 7: Storm water retention at the U of Arizona. 


\subsection{Water reuse}

Reusing rainwater or greywater for toilet flushing or irrigation. Using high efficiency and low flow appliances, can have a significant impact in decreasing the amount of potable water used in a building, particularly for commercial and institutional buildings where toilet flushing comprises a large percentage of water use. There are many ancillary environmental benefits to utilizing water reuse systems: reduced overall demand for potable water conserves fresh water sources, which saves energy used in the treatment and conveyance of municipally supplied water, prevents flooding, protects water quality through diminished CSOs, and improves community water assets for recreation and wildlife habitat.

In 2001, the Arizona Department of Environmental Quality (ADEQ) regulated the use of residential greywater. This ruling made it possible to use greywater for landscape irrigation. In the following example, greywater from cloth washer, bathtubs, showers, bath sinks, and condensate water from the two heat pumps was collected in a dedicated 4" greywater PVC pipe towards a mixing/switching valve on the east side of the house that diverts the water to the 2000 gallon septic tank with 4-50' long leach fields.
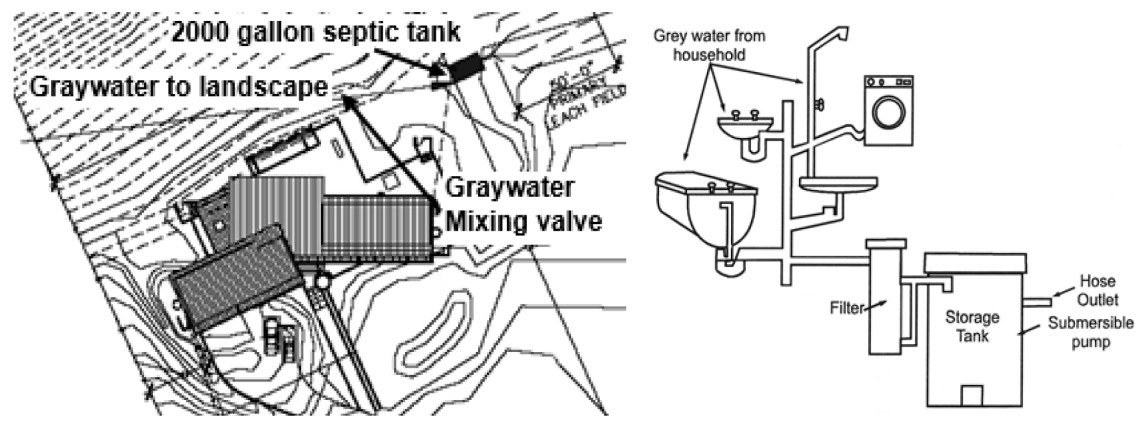

Figure 8: Greywater reuse.

\subsection{Water energy generation}

Energy generation from water is a fairly new field of knowledge and the technology is emerging. Although not many methods are available, the authors have introduced the algae façade to the Engineering Innovation Building (EIB) on UA Campus [8].

A $1,440 \mathrm{ft}^{2}$ south oriented bio-adaptive algae façade was developed to generate about $9,400 \mathrm{kWh}$ annually. Initially, the design opted to distinguish the water types and then planned methodologies to harvesting process; afterwards, incorporated a bio-skin façade where an adaptive algae façade was introduced on the southeast corner of the building. This façade requires liquid nutrients and carbon dioxide via a separate water circuit to produce microalgae that are transformed to biogas, which is one source of production of energy. Therefore, this approach has functioned in 3 ways: (1) produce renewable energy, (2) utilizes greywater to feed the algae, (3) sustain shading to the building. 


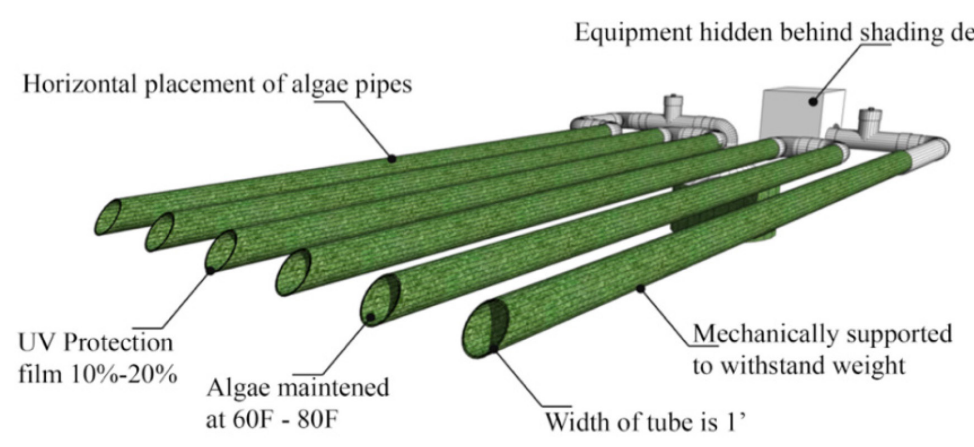

Figure 9: Algae tubing.

Evaluating the Energy Use Intensity (EUI) of the EIB showed a substantial energy savings due to the algae panels shading the southeast façade of the building; therefore, water engages and serves several valuable environment goals.

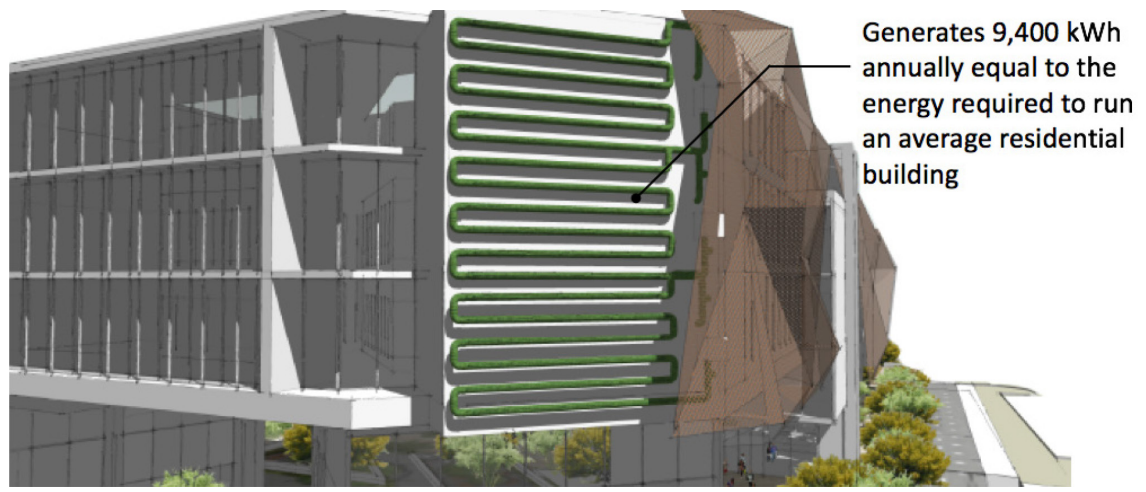

Figure 10: Algae application.

Finally, the benefits of the algae wall has been initiated as an awareness strategy to educate the users of the building and the public; exhibiting greywater usage, shading, and energy conservation.

\section{Conclusion}

Water and energy can no longer be treated as separate disciplines as they have major impacts on each other as well as the buildings sector and the built environment contributing to climate change. Architects, developers, and city planners can play a major role in adopting strategies that affect water/energy consumption. In today's education system, there is a need to inform designers about integrating water and energy systems, to encourage them to research and develop methods and disseminate. Architecture design and professional practice has the opportunity to overcome the current high consumption of energy by integrating smart water saving, harvesting, and reusing techniques. Integrate 
emerging technologies of generating energy from water. At the University of Arizona, College of Architecture, Planning and Landscape Architecture, a fourlegged water education curriculum has been developed by Dr. Nader Chalfoun, and Omar Youssef, experimentally implemented in a graduate design studio where students' projects emphasized the use of water strategies. These methods are now taught in a newly offered course at the graduate level.

\section{References}

[1] Gleick, P.H. (1993). Water in crisis: a guide to the world's fresh water resources. Oxford University Press, Inc.

[2] Oki, T. and Kanae, S. (2006). Global hydrological cycles and world water resources. Science, 313(5790), 1068-1072.

[3] Chalfoun, N.V. and Youssef, O. (2015). "Water is not merely for human consumption, water is essential in the design, construction, and operation of the built environment," Universities Council on Water Resources (UCOWR) Conference, June 16-18, Las Vegas, Nevada, USA.

[4] Youssef, O. (2016). "Water integration sustainable design strategies," Universities Council on Water Resources (UCOWR) Conference, June 2124, Pensacola, Florida, USA.

[5] Chalfoun, N.V. and Youssef, O. (2015). "Developing and integrating water curricula in architecture education and design application," Universities Council on Water Resources (UCOWR) Conference, June 16-18, Las Vegas, Nevada, USA.

[6] Pérez-Lombard, L., Ortiz, J. and Pout, C. (2008). A review on buildings energy consumption information. Energy and Buildings, 40(3), 394-398.

[7] Chalfoun, N.V. (2010). "Passive and active," A Sustainable Single Family Residence in Tubac Arizona, the 2010 Hawaii International Conference on Arts and Humanities, January 13-16, Honolulu, Hawaii, USA.

[8] Elzomor, M. and Youssef, O. (2015). "Living and learning in practice: University of Arizona Engineering Innovation Building (EIB)," Research for a Better Built Environment: 49th International Conference of the Architectural Science Association, pp.33-44, The Architectural Science Association and The University of Melbourne. 